\title{
Young adult patient with headache, fever and blurred vision
}

\author{
Stavroula A. Paschou, ${ }^{1}$ Konstantinos Tzioras, ${ }^{1}$ Vasiliki Trianti, ${ }^{1}$ Stavroula Lyra, ${ }^{2}$ \\ Vasileios-Arsenios Lioutas, ${ }^{3}$ Andreas Seretis, ${ }^{4}$ Andromachi Vryonidou ${ }^{1}$
}

${ }^{1}$ Department of Endocrinology and Diabetes, ${ }^{2}$ Department of Radiology, Hellenic Red Cross Hospital, Athens, Greece; ${ }^{3}$ Department of Neurology, Beth Israel Deaconess Medical Center, Harvard Medical School, Boston, MA, USA; ${ }^{4}$ Department of Neurosurgery, "G. Gennimatas" General Hospital, Athens, Greece

\begin{abstract}
BACKGROUND AND IMPORTANCE: This case highlights the fact that acute pituitary apoplexy may be misdiagnosed due to being confused with other entities exhibiting similar symptoms, such as meningitis or subarachnoid hemorrhage. CLINICAL PRESENTATION: A patient in his late 30s presented with sudden and severe frontal headache, fever, blurred vision, nausea, confusion, as well as oculomotor palsy (CN III) with partial ptosis of the left eyelid, dilated left pupil and left eye globe deviation inferiorly and laterally. The final diagnosis was acute pituitary apoplexy complicating a pituitary macroadenoma. In this setting, headache is usually present due to stretching and irritation of the dura mater, and fever due to meningeal irritation or upward expansion leading to hypothalamic dysfunction. Decreased visual acuity and defects in visual fields are caused by upward expansion, which compresses the optic chiasm. Ophthalmoplegia can also be observed due to lateral expansion with invasion of the cavernous sinus. CONCLUSION: Medical professionals involved in emergency care should be aware of this clinical entity and collaborate with endocrinologists using a multidisciplinary team approach for prompt diagnosis and optimal treatment of such patients.
\end{abstract}

Key words: Apoplexy, Headache, Pituitary, Macroadenoma, Ophthalmoplegia

\section{CASE PRESENTATION}

A 37-year old Greek man presented at the emergency department of our hospital with sudden and severe frontal headache, fever, blurred vision, nausea and confusion. Nothing was notable from his medical or family history; he did not smoke and was not tak-

\footnotetext{
Address for correspondence:

Dr. Andromachi Vryonidou, MD, PhD, Department of Endocrinology and Diabetes, Hellenic Red Cross Hospital, 1 Athanasaki Str., 11526 Athens, Greece; Tel.: +30 210 6135521, E-mail: mahi_vr@hotmail.com

Received: 07-09-2016, Accepted: 29-09-2016
}

ing any drugs. On physical examination, fever was confirmed $\left(\mathrm{T}=38.7^{\circ} \mathrm{C}\right)$, mild hypotension was observed ( $\mathrm{BP}=100 / 65 \mathrm{mmHg}, \mathrm{HR}=70 \mathrm{bpm}$ ), while his ECG was normal. Neck stiffness, as well as oculomotor palsy (CN III) with partial ptosis of the left eyelid, dilated left pupil and left eye globe deviation inferiorly and laterally were revealed. Visual acuity was decreased (right 9/10, left 8/10), while visual fields testing showed a bitemporal superior quadratic defect, without any papilledema in fundoscopy. Laboratory evaluation revealed: $\mathrm{WBC}=18,500$ with neutrophils in $90.2 \%$, $\mathrm{CRP}=14.6 \mathrm{mg} / \mathrm{L}$, sodium $=134 \mathrm{mEq} / \mathrm{l}$. Brain $\mathrm{CT}$ scan 
did not show any sign of subarachnoid hemorrhage, but revealed a pituitary mass (Figure 1). Lumpar

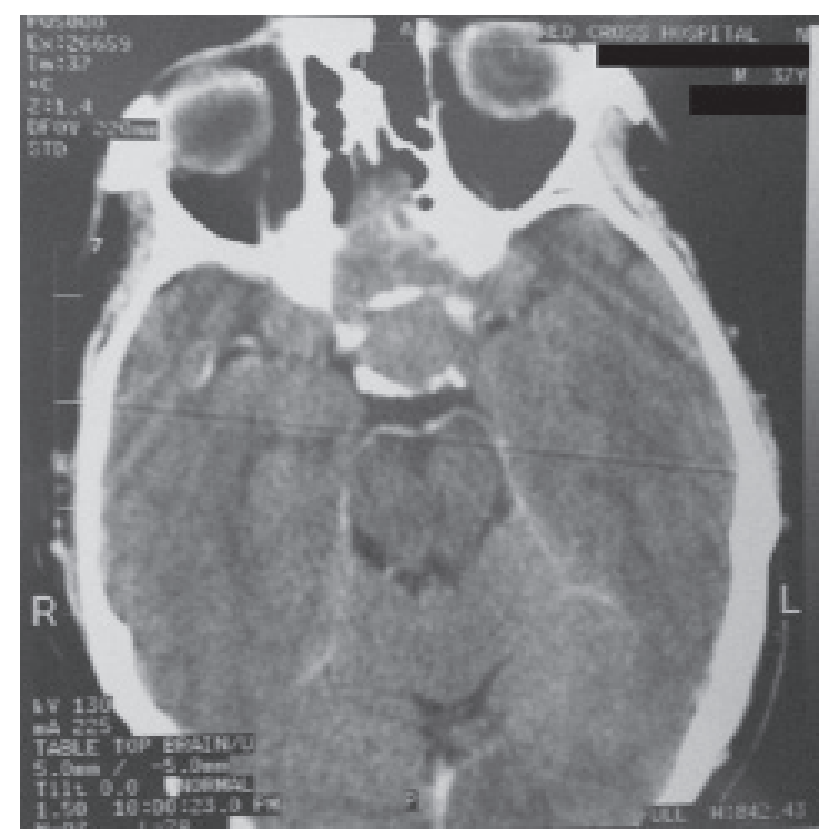

Figure 1. Brain CT scan revealing a pituitary mass puncture was also performed, but cerebrospinal fluid analysis was unremarkable.

\section{DISCUSSION}

The diagnosis is acute pituitary apoplexy complicating a pituitary macroadenoma. Pituitary magnetic resonance imaging ( 1 day after the patient's admission to the emergency department) confirmed the diagnosis, indicating a macroadenoma, $2.8 \times 1.8 \times 1.8 \mathrm{~cm}$ in size with apoplexy (Figure 2). Endocrine investigation showed hypopituitarism, with random cortisol during fever: $13 \mu \mathrm{g} / \mathrm{dl}$ (in critically ill patients random cortisol levels lower than $15 \mu \mathrm{g} / \mathrm{dl}$ strongly suggest adrenal insufficiency, in this case compromised HPA axis reserve), FT4: $0.58 \mathrm{ng} / \mathrm{dl}(0.7-1.8), \mathrm{TT}: 0.7 \mathrm{ng} /$ $\mathrm{ml}$ (2.4-10), IGF-1: $71 \mathrm{ng} / \mathrm{mL}(177-382)$ and PRL: $1.9 \mathrm{ng} / \mathrm{ml}$ (3.2-19). After hydration and replacement therapy with dexamethasone (presenting stronger antiedema effects compared to hydrocortisone) and levothyroxine, the patient's symptoms gradually improved. Transsphenoidal surgery was performed 11 days after the initial admission and the pathology
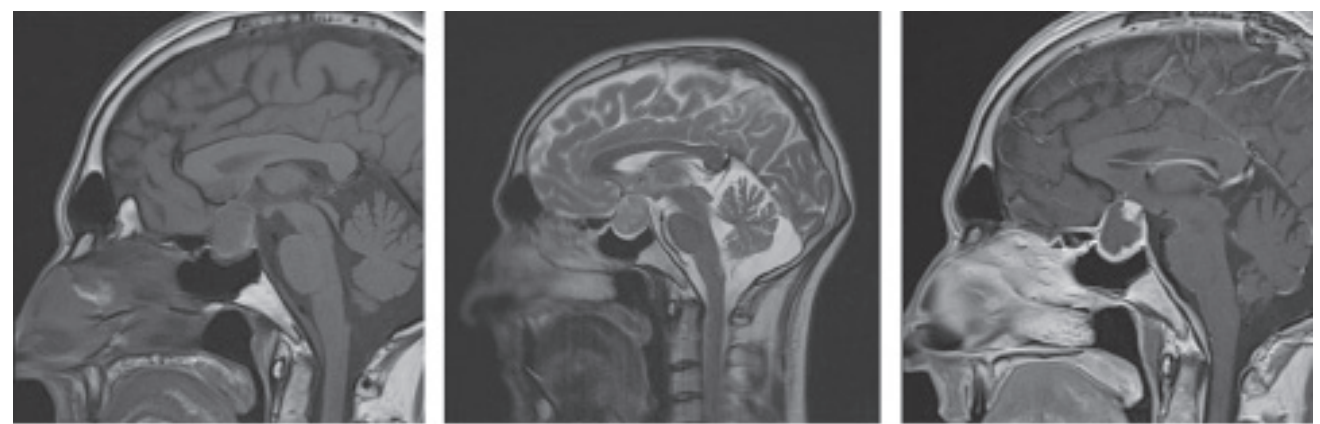

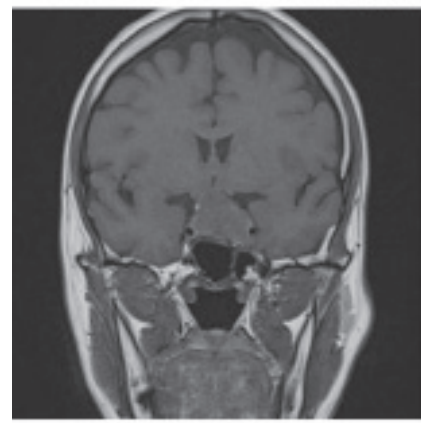

T1W

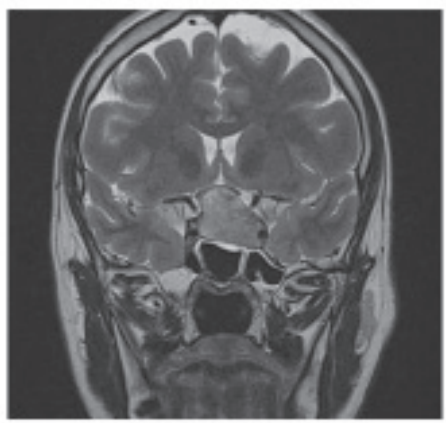

$\mathrm{T} 2 \mathrm{~W}$

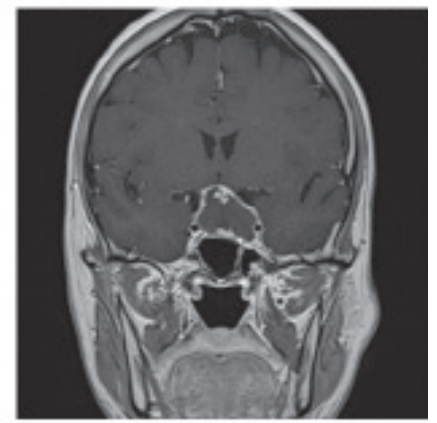

$\mathrm{T} 1 \mathrm{~W}+\mathrm{GD}$

Figure 2. Pituitary MRI indicating macroadenoma, $2.8 \times 1.8 \times 1.8 \mathrm{~cm}$ in size with apoplexy. Sagittal and coronal sections of precontrast T1-weighted, T2-weighted and gadolinium (Gd)-enhanced T1-weighted images are presented. Enlargement of the pituitary fossa, superior expansion of the macroadenoma and compression of the optic chiasm, as well as lateral extension into the left cavernus sinus are obvious. Post-Gd enhancement is only peripheral due to the hemorrhagic infarction. 
examination revealed a gonadotroph pituitary adenoma positive for $\beta-\mathrm{FSH}$ with hemorrhage and necrosis areas consistent with apoplexy. Immunostaining for other pituitary hormones was negative. One year after the initial admission, the patient presents no signs or symptoms and is on replacement treatment only with levothyroxine (Figure 3). It is interesting that the patient has isolated TSH deficiency; it would have been expected that other anterior pituitary hormone deficits would be expected to be present too. Nevertheless, several surgical series of pituitary adenomas have shown that hypopituitarism can improve with surgery. ${ }^{1,2}$

Acute pituitary apoplexy is sometimes the first clinical presentation in patients with macroadenomas. Headache is usually present due to stretching and ir-

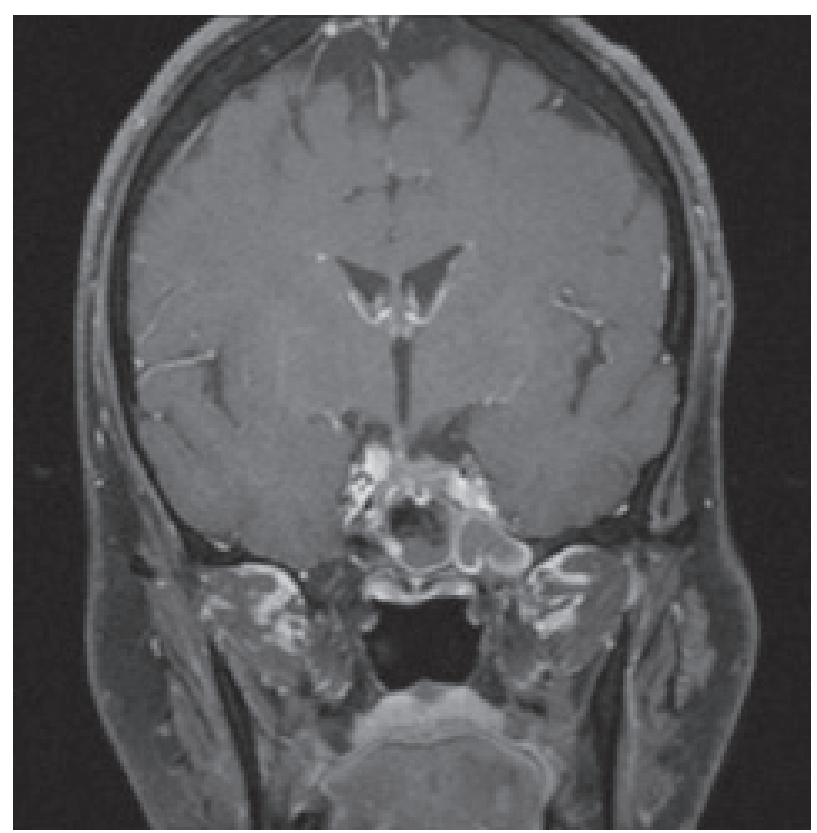

Figure 3. Post transsphenoidal surgery pituitary MRI. Gd-enhanced T1-weighted coronal image is presented. Changes in anatomical conditions after surgery as well as implanted material (fat) within the pituitary fossa are obvious. ritation of the dura mater and fever due to meningeal irritation or upward expansion leading to hypothalamic dysfunction. Decreased visual acuity and defects in visual fields are caused by upward expansion, which compresses the optic chiasm. Ophthalmoplegia can also be observed due to lateral expansion with invasion of the cavernous sinus. Therefore, acute pituitary apoplexy can potentially be misdiagnosed due to being confused with other entities exhibiting similar symptoms, such as meningitis or subarachnoid hemorrhage. Medical professionals involved in emergency care should be aware of this clinical entity and collaborate with endocrinologists employing a multidisciplinary team approach for timely diagnosis and optimal treatment of such patients..$^{3-5}$

\section{CONFLICT OF INTEREST}

None.

\section{DISCLOSURE OF FUNDING}

None.

\section{REFERENCES}

1. Arafah BM, 1986 Reversible hypopituitarism in patients with large nonfunctioning pituitary adenomas. J Clin Endocrinol Metab 62: 1173-1179.

2. Arafah BM, Kailani SH, Nekl KE, Gold RS, Selman WR, 1994 Immediate recovery of pituitary function after transsphenoidal resection of pituitary macroadenomas. J Clin Endocrinol Metab 79: 348-354.

3. Capatina C, Inder W, Karavitaki N, Wass JA, 2015 Management of endocrine disease: pituitary tumour apoplexy. Eur J Endocrinol 172: R179-190.

4. Rajasekaran S, Vanderpump M, Baldeweg S, et al, 2011 UK guidelines for the management of pituitary apoplexy. Clin Endocrinol (Oxf) 74: 9-20.

5. Paschou SA, Vryonidou A, Goulis DG, 2016 Pituitary incidentalomas: A guide to assessment, treatment and follow-up. Maturitas 92: 143-149. 